\title{
Introduction to the Seniors' Use of Health Information Technology Minitrack
}

\author{
Heiko Gewald \\ Neu-Ulm University of Applied Sciences \\ heiko.gewald@hs-neu-ulm.de
}

\author{
Wendy Currie \\ Audencia Business School \\ wcurrie@audencia.com
}

By 2050, two billion people, nearly one in four people, will be older than 60 years (WHO, 2015). This demographic effect puts tremendous pressure on social systems around the world. The intelligent use of information technology can provide a way to deal with this upcoming issue by enabling senior's to live a longer self-directed living.

Currently, our knowledge on the impact of age on technology use is rather limited. Research found that seniors react differently and can also be very tech savvy. However, we are far away from having a good understanding of motivational factors for the elderly. On top of this, we see the phenomenon of "perceived age", i.e. people tend to behave as if they were younger than their physical age. "70 is the new 50" is a phrase which gains importance every year. Studies show, that today's 70 year olds are cognitive on the level of 50 year old people (SOEP, 2015). This calls for more research on the question whether academics should continue to work with "age" as a control variable, or a shift towards "perceived age" is necessary. Needless to say that this requires work to develop the corresponding measurement items.

In summary it can be said that senior's use of information technology and specifically health IT is a topic which requires research for the years to come. In doing this, the IS community is looking forward to developing solutions that matter for our future society. In this mini-track, seven papers focus on how health information technology (HIT), including electronic health (eHealth) and mobile health (mHealth) provides solutions for an increasingly elderly population.
Robert Rockman and Heiko Gewald. "Older Adults' Use of Online Health Information Do They Try?".

Sarah Alismail, Hind Bitar, Swati Ramani. "How to Motivate Adults to Check for Alzheimer's Disease (AD) Using Three Types of Triggers".

Thi Thanh, Hai Nguyen, Diana Ishmatova, Tommi Tapanainen, Tapani N. Liukkonen, Niina Katajapuu, Tuomas Makila, Mika Luimula. "Impact of Serious Games on Health and Well-being of Elderly: A Systematic Review".

Iyubanit Rodrigues, Carolina Fuentes, Valeria Herskovic, Jose A. Pino. "Are Notifications a Challenge for Older People?: A Study Comparing Two Types of Notifications".

Suchada Vichitvanichphong, Amir Talaei, Donald Kerr. "Elderly's Perception about the Value of Assistive Technologies for their Daily Living: Impacting Factors and Theoretical Support".

Friederike Boll, Phillip Brune, Heiko Gewald. "Towards your Parents' Social Network Platform: Design of a User Interface for the Age of Retirement".

Mirou Jaana, Haitham Tamim, Healther Sherrard, Guy Pare, Rosta Farzen, Charles Jonassaint. "Telemonitoring for Seniors with Chronic Heart Failure: Patient Self-Care, Empowerment, and Adoption Factors".

\section{References}

SOEP, 2015, The German Socio-Economic Panel study at DIW Berlin, Secular Changes in Late-life Cognition and Well-being: Towards a Long Bright Future with a Short Brisk Ending?, Study 738-2015

World Health Organization, 2015, Ageing and health, Fact sheet $\mathrm{N}^{\circ} 404$ 